\title{
Produção de Leite, Consumo e Digestibilidade Aparente dos Nutrientes, pH e Concentração de Amônia Ruminal em Vacas Lactantes Recebendo Rações Contendo Silagem de Milho e Fenos de Alfafa e de Capim-Coastcross ${ }^{1}$
}

\section{Andréia Luciane Moreira2 ${ }^{2}$, Odilon Gomes Pereira ${ }^{3,5}$, Rasmo Garcia ${ }^{3,5}$, Sebastião de Campos Valadares Filho ${ }^{3,5}$, José Maurício de Souza Campos ${ }^{3}$, Viviane Glaucia de Souza ${ }^{4}$, Joanis Tilemahos Zervoudakis ${ }^{4}$}

\begin{abstract}
RESUMO - Utilizaram-se 10 vacas lactantes HPC e mestiças H*Z, com 55 dias de parição, peso médio de $540 \mathrm{~kg}$, distribuídas em um delineamento em switch-back com o objetivo de avaliar a produção e a composição do leite, o consumo e a digestibilidade aparente de matéria seca (MS), matéria orgânica (MO), fibra em detergente neutro (FDN), proteína bruta (PB), carboidratos totais (CT) e extrato etéreo (EE), e o pH e a concentração de amônia ruminal. Os animais foram alimentados ad libitum com cinco dietas contendo silagem de milho (SM), feno de alfafa (FA), feno de capim-coastcross (FCC), 1/2 FA+1/2 SM, 1/2 FCC+1/2 SM, na proporção de $60 \%$, da ração total (base de matéria seca). Os consumos dos nutrientes não foram influenciados pelas dietas. As digestibilidades aparentes de MS, PB e FDN foram maiores para as dietas contendo silagem de milho. O pHe a concentração de amônia do líquido ruminal não foram influenciados pelas dietas, porém observou-se resposta quadrática para o tempo de coletas. Registrou-se maior produção de leite para os animais que receberam silagem de milho. Os teores de proteína bruta e gordura do leite não foram influenciados pelas dietas.
\end{abstract}

Palavras-chave: composição do leite, fibra em detergente neutro, matéria seca, proteína bruta

\section{Milk Yield, Intake and Apparent Digestibility of Nutrients, pH and Ruminal Ammonia Concentration in Lactating Cow Fed Diets Containing Corn Silage and Alfalfa and Coastcross Bermudagrass Hays}

\begin{abstract}
Ten lactating cows (Holtein and $\mathrm{H}^{*} \mathrm{Z}$ crossbreed) after $55 \mathrm{~d}$ calving, with average weigth of $540 \mathrm{~kg}$ alloted to a switchback design, were used in order to evaluate the intake and apparent digestibilities of dry matter (DM), organic matter (OM), neutral detergent fiber (NDF), crude protein (CP), total carbohydrates (TC) and ether extract (EE), the $\mathrm{pH}$ and ruminal ammonia concentration and milk yield and composition. The animals were fed ad libitum with diets containing alfalfa hay (AH), coastcross bermudagrass hay $(\mathrm{CCH})$, corn silage (CS), $1 / 2 \mathrm{AH}+1 / 2 \mathrm{CS}$ and and $1 / 2 \mathrm{CCH}+1 / 2 \mathrm{CS}$ in $60 \%$ of the total diet (dry matter basis). The nutrients intake were not affected by the diets. The dry matter, crude protein and neutral detergent fiber apparent digestibilities were higher for diets with corn silage. The experimental diets did not affect $\mathrm{pH}$ and the ruminal ammonia concentration, however quadratic effect was observed for collection time. The highest milk productions were observed for the animals that received CS and $1 / 2 \mathrm{AH}+1 / 2 \mathrm{CS}$ diets. The diets did not affect the crude protein and fat milk contents.
\end{abstract}

Key Words: crude protein, dry matter, neutral detergent fiber, milk composition

\section{Introdução}

A alimentação racional dos animais domésticos visa fornecer os nutrientes capazes de manter e assegurar as exigências de mantença e o nível de produção pretendido. Dessa forma, verifica-se que a nutrição de vacas lactantes constitui a base do sucesso de uma exploração leiteira, visto que os custos dos alimentos representam mais da metade do custo da produção, o que exercerá, sem dúvida, grande influ- ência sobre a rentabilidade de todo o processo produtivo. Dessa forma, para uma exploração leiteira lucrativa, é necessário que se trabalhe com animais de alto potencial genético, submetidos às condições alimentares que permitam obter altas produções, a custos mais econômicos. Isto se torna possível, principalmente, por intermédio de adequado manejo nutricional, reprodutivo e sanitário.

Para categorias animais que apresentam requerimentos nutricionais mais altos, o feno e, ou, a silagem

\footnotetext{
1 Parte da tese de Mestrado do primeiro autor, parcialmente financiada pela FAPEMIG/CNPq.

2 Estudante de Doutorado - FCAV/UNESP - 14870-000 Jaboticabal, SP.

3 Professor do DZO/UFV - 36570-000 - Viçosa, MG.

4 Estudante de Doutorado - UFV/DZO - 36570-000 Viçosa, MG.

5 Bolsista do CNPq.
} 
de gramíneas podem ser incapazes de manter altos desempenhos, se os mesmos constituírem a maior porção da dieta (VAN SOEST, 1965). Dessa forma, a nutrição de animais, visando à produção leiteira ou de carne, necessita de forragens com alta qualidade de modo a obter redução nos custos provenientes da utilização de concentrados, visando ao fornecimento de energia e, ou, proteína para o animal, sem, contudo, comprometer o desempenho animal.

A ingestão de matéria seca é um dos fatores determinantes do desempenho animal, sendo o ponto inicial para o ingresso de nutrientes, principalmente de energia e proteína, necessários para o atendimento das exigências de mantença e produção, enquanto a digestibilidade e a utilização de nutrientes representam apenas a descrição qualitativa do consumo (NOLLER et al., 1997).

A utilização de duas forrageiras misturadas em dietas de vacas lactantes, segundo DHIMAN e SATTER (1997), é uma prática de manejo nutricional que induz maior uniformização no consumo de nutrientes, retirando, dessa forma, os riscos decorrentes da falta de algum nutriente, que por ventura, possa ocorrer, por intermédio de diversos fatores ambientais.

Em estudos conduzidos por BELYEA et al. (1974), HOLTER et al. (1974) e GRIEVE et al. (1980), visando avaliar o consumo, a digestibilidade e a produção de leite de vacas lactantes recebendo silagem de milho, silagem de milho associada à silagem pré-secada de alfafa e silagem de milho associada ao feno de alfafa, as dietas não exibiram diferenças marcantes quanto aos parâmetros avaliados.

CODAGNONE et al. (1988), trabalhando com silagem de milho e feno de aveia para vacas lactantes, nas proporções de 100:0; 74,7:25,3; 53,8:46,2; 28,6:71,4; e 0:100, e suplementação diária de $3,5 \mathrm{~kg}$ de concentrado/vaca, obtiveram consumos médios diários de 13,3; 13,4; 13,9; 14,0; e 13,3 kg MS/animal, correspondendo a 2,$8 ; 2,8 ; 2,9 ; 3,0 ;$ e $2,8 \%$ de peso vivo $(\mathrm{PV})$, respectivamente, que não diferiram entre as dietas. Os autores atribuíram este fato à suplementação ocorrida no decorrer do experimento.

Em virtude de a proteína ser um dos ingredientes mais caros da dieta, a economia da produção animal é altamente dependente da eficiência de sua utilização. Por esse motivo, nos últimos anos, tem havido considerável interesse na redução das perdas de compostos nitrogenados (N) pelos ruminantes (RUSSEL, 1992).

Vacas em lactação têm alto requerimento de proteína, principalmente, no início da lactação. Vári- os estudos têm relatado altos rendimentos de leite, quando o consumo de proteína bruta se eleva. Comparando silagem de alfafa e silagem de milho como fonte única de volumoso para vacas em lactação, em dietas com $60 \%$ de silagem de alfafa, $60 \%$ de silagem de milho ou $79 \%$ de silagem de milho, na base da matéria seca, BRODERICK (1985) concluiu que a silagem de alfafa é comparável à de milho para a produção de leite, sem afetar a concentração de gordura do mesmo.

Sumarizando uma série de experimentos, SCHINGOETHE (1984) relatou que uma redução na proteína degradável no rúmen, somada ao aumento na proteína de escape, acarretou aumento na quantidade de proteína do leite produzida por kg de proteína bruta (PB) consumida, quando as fontes energéticas permaneceram constantes. Todavia, não se verificaram variações na proteína do leite, com o incremento do teor de carboidratos solúveis nas dietas.

A concentração de amônia no líquido ruminal é consequiência do equilíbrio entre sua produção, utilização pelos microrganismos e absorção pela parede ruminal, sendo que a utilização pelos microrganismos depende da quantidade de energia disponível. A maioria das bactérias ruminais é capaz de utilizar amônia como fonte de nitrogênio para síntese de proteína microbiana, mas a fermentação ruminal da proteína, freqüentemente, produz mais amônia que os microrganismos podem utilizar. Em muitos casos, mais de $25 \%$ da proteína podem ser perdidas como amônia. Em razão de ser um dos ingredientes mais caros nas dietas de ruminantes, existe considerável interesse na redução da fermentação ruminal de proteína (RUSSELL et al., 1992).

Os níveis de amônia no rúmen são importantes na síntese de proteína microbiana. Assim, SATTER e SLYTER (1974) e COLLINS e PRITCHARD (1992) verificaram que concentração de 5 a $8 \mathrm{mg}$ de $\mathrm{N}-\mathrm{NH}_{3} /$ $100 \mathrm{~mL}$ de líquido ruminal é suficiente para suportar a taxa máxima de crescimento das bactérias ruminais. Entretanto, estudos sugerem que a concentração de amônia para a máxima síntese de proteína microbiana pode ser de 15 a $20 \mathrm{~N}-\mathrm{NH}_{3} / 100 \mathrm{~mL}$ de fluido, dependendo da dieta (LENG e NOLAN, 1984). Adicionalmente, OBARA et al. (1991) relataram que maior contribuição de amônia, normalmente, decorre da degradação microbiana do nitrogênio dietético não-amoniacal, sendo que as dietas com feno, silagem e forragem fresca podem contribuir com até $48 ; 64$; e $80 \%$, respectivamente. 
$\mathrm{O}$ pH ruminal é um importante parâmetro a ser avaliado, pois reflete diretamente as características da dieta, além de afetar não só produtos finais da fermentação, mas também a taxa de crescimento das bactérias e dos protozoários, podendo, dessa forma, ocorrer variações nos microrganismos predominantes no rúmen (LAVEZZO et al., 1998).

A diminuição do $\mathrm{pH}$ reduz a degradabilidade da proteína, celulose, hemicelulose e pectina, embora seus efeitos sejam menores sobre a digestão do amido (HOOVER e STOKES, 1991). Caso ocorra redução moderada no $\mathrm{pH}$ ruminal, até aproximadamente 6,0, a digestão da fibra decresce moderadamente, embora o número de microrganismos fibrolíticos não seja normalmente influenciado. Quando o pH atinge a faixa de 5,5 a 5,0, ocorre a redução do número de microrganismos fibrolíticos, bem como suas taxas de crescimento, podendo causar inibição na digestão da fibra (HOOVER, 1986). O pH do fluido ruminal pode variar entre 5,5 e 6,5, para dietas concentradas, e 6,2 e 7,0, para dietas constituídas exclusivamente de volumosos. Segundo HOOVER (1986), a faixa de $\mathrm{pH}$ ideal para a ótima digestão da fibra varia de 6,2 a 7,0. Entretanto, VAN SOEST (1994) sugere que este valor seria de 6,7.

Trabalhos realizados com fenos de capim-elefante, rama de mandioca, e palha de arroz com alto conteúdo de parede celular, suplementados com proteína e, ou, energia, não apresentaram variações no $\mathrm{pH}$, que se manteve em torno de 6,7 (GOMES, 1991; AMARAL, 1994).

O presente trabalho foi desenvolvido com o objetivo de avaliar a produção de leite e seus teores de proteína bruta e gordura, o consumo e as digestibilidades aparentes dos nutrientes, o $\mathrm{pH}$ e a concentração de amônia no líquido ruminal, em vacas lactantes recebendo rações contendo silagem de milho e fenos de alfafa e de capim-coastcross, como fonte de volumoso.

\section{Material e Métodos}

O experimento foi conduzido no Departamento de Zootecnia da Universidade Federal de Viçosa (UFV), Viçosa, Minas Gerais. Foram usadas 10 vacas lactantes, entre a $3^{\underline{a}}$ e $6^{\underline{a}}$ lactações, com grau de sangue variando de HPC a mestiço Holandês x Zebu (1/2 HxZ a 15/16 HxZ), peso vivo médio de $540 \mathrm{~kg}$ e, em média, 55 dias de parição, distribuídas em delineamento experimental em switch-back reduzido, constituído de dois blocos, segundo LUCAS (1956), no qual cada período obteve duração de 21 dias e cada seqüência de tratamento correspondeu a um animal.

Foram avaliadas cinco dietas, adotando-se relação volumoso: concentrado de 60:40, na base da matéria seca, utilizando uma ração concentrada para cada volumoso. Os volumosos foram constituídos de feno de alfafa (FA), feno de capim-coastcross (FCC), silagem de milho (SM), $50 \%$ de feno de alfafa $+50 \%$ de silagem de milho $(\mathrm{FA}+\mathrm{SM})$, e $50 \%$ de feno de capim-coastcross $+50 \%$ de silagem de milho $(\mathrm{FCC}+\mathrm{SM})$. As dietas totais, foram calculadas para conter aproximadamente, $16,0 \% \mathrm{~PB}$, de modo a atenderem os requerimentos de proteína para uma vaca de $540 \mathrm{~kg}$ de peso vivo, produzindo $22 \mathrm{~kg}$ de leite, corrigido a 4\% de gordura, segundo o NRC (1989). A composição percentual dos ingredientes das rações concentradas encontra-se na Tabela 1 e as composições bromatológicas dos volumosos e concentrados, na Tabela 2. Na Tabela 3, encontra-se a composição bromatológica das dietas experimentais.

A alimentação foi fornecida em duas refeições diárias, às 7 e 15h30, ad libitum, de modo a proporcionar sobras em torno de $10 \%$. Durante o fornecimento da alimentação, efetuou-se manualmente a mistura de concentrados e volumosos, no comedouro.

Os animais foram mantidos em baias individuais, cobertas com piso cimentado, contendo comedouros e bebedouros individuais. O piso era limpo (rapado), quando necessário, e lavado todos os dias, às $23 \mathrm{~h}$, quando os animais eram levados a um curral, próximo às baias, cimentado, com água à vontade, onde passavam a noite, para se exercitarem e descansarem, retornando para suas baias às $6 \mathrm{~h}$ do dia seguinte.

A pesagem dos animais foi realizada após a ordenha da manhã, no início e no final de cada período experimental. Para a produção de leite, foram considerados os dados obtidos do $8^{\circ}$ ao $21^{\mathrm{o}}$ dia, em cada período, referentes à composição do leite (gordura e proteína) e ao consumo e à digestibilidade dos nutrientes. No $21^{\circ} \underline{ }$ dia, coletou-se amostras de líquido ruminal, para medição do pH e da concentração de amônia.

A pesagem do leite foi realizada diariamente, sendo coletadas amostras de $400 \mathrm{~mL}$ no $16^{\circ}, 18^{\circ}$ e $20^{\circ}$ dia de cada período, as quais foram analisadas logo após as ordenhas da manhã e da tarde, para determinação da densidade, por meio de termolactodensímetro, e da matéria gorda do leite, pelo método de Gerber (BEHMER, 1984). As amostras da manhã e tarde, oriundas do $18^{\circ}$ dia eram misturadas proporcionalmente e analisadas quanto ao teor de nitrogênio total pelo método micro Kjeldhal (SILVA, 1990). 
1092 Tabela 1 - Composição percentual das rações

Table 1 - Ingredient composition of concentrate rations

\begin{tabular}{|c|c|c|c|c|c|}
\hline \multirow[t]{2}{*}{$\begin{array}{l}\text { Ingredientes } \\
\text { Ingredient }\end{array}$} & \multicolumn{5}{|c|}{$\begin{array}{c}\text { Rações concentradas }(\mathrm{C}) \\
\text { Concentrate rations }(C)\end{array}$} \\
\hline & $\mathrm{Cl}$ & $\mathrm{C} 2$ & C3 & $\mathrm{C} 4$ & C5 \\
\hline $\begin{array}{l}\text { Fubá de milho } \\
\text { Ground corn }\end{array}$ & 97,29 & 59, & 40,80 & 68,85 & 49,33 \\
\hline $\begin{array}{l}\text { Farelo de soja } \\
\text { Soybean meal }\end{array}$ & - & 36,42 & 55,63 & 27,82 & 46,17 \\
\hline $\begin{array}{l}\text { Sal } \\
\text { Salt }\end{array}$ & 1,00 & 1,00 & 1,00 & 1,00 & 1,00 \\
\hline $\begin{array}{l}\text { Fosfato bicálcico } \\
\text { Dicalcium phosphate }\end{array}$ & 1,66 & 1,61 & 1,44 & 2,28 & 2,89 \\
\hline $\begin{array}{l}\text { Calcário calcítico } \\
\text { Limestone }\end{array}$ & - & 1,35 & 1,08 & - & 0,56 \\
\hline $\begin{array}{l}\text { Micronutrientes } \\
\text { Micronutrients }^{1}\end{array}$ & 0,05 & 0,05 & 0,05 & 0,05 & 0,05 \\
\hline
\end{tabular}

$181,5 \%$ de sulfato de zinco (zinc sulfate); $17,52 \%$ de sulfato de cobre (cupper sulfate); $0,48 \%$ de iodato de potássio (potassium iodate); $0,32 \%$ de selenito de sódio (sodium selenite) e $0,18 \%$ de sulfato de cobalto (cobalt sulfate).

No $21^{\underline{0}}$ dia de cada período experimental, foram realizadas coletas de líquido ruminal, utilizando-se a técnica da sonda esofágica, segundo ORTOLANI (1981), para determinação do pH e da concentração de amônia, no tempo zero (antes da alimentação) e 2, 4 e 6 horas após a alimentação matutina. Logo após, determinou-se o $\mathrm{pH}$, por meio de um peagâmetro digital. Em seguida, realizou-se a filtragem do mesmo

Tabela 2 - Composição bromatológica das forragens e das rações concentradas $(\mathrm{C} 1, \mathrm{C} 2, \mathrm{C} 3, \mathrm{C} 4, \mathrm{C} 5)$

Table 2 - Chemical composition of forages and concentrates rations $(C 1, C 2, C 3, C 4, C 5)$

\begin{tabular}{|c|c|c|c|c|c|c|}
\hline $\begin{array}{l}\text { Alimer } \\
\text { Feed }\end{array}$ & MS \% & MO & $\begin{array}{l}\mathrm{PB} \\
C P\end{array}$ & $\begin{array}{l}\mathrm{EE} \\
E E\end{array}$ & $\begin{array}{l}\text { CT } \\
\text { TC }\end{array}$ & $\begin{array}{l}\text { FDN } \\
N D F\end{array}$ \\
\hline & \multicolumn{6}{|c|}{$\begin{array}{l}\% \text { na } \mathrm{MS} \\
\% \text { in } D M\end{array}$} \\
\hline $\begin{array}{l}\text { Feno de alfafa } \\
\text { Alfalfa hay }\end{array}$ & 81,57 & 90,19 & 18,20 & 0,84 & 71,15 & 51,03 \\
\hline $\begin{array}{l}\text { Feno de capim- } \\
\text { coastcross }\end{array}$ & 84,35 & 94,66 & 10,46 & 0,73 & 83,47 & 75,98 \\
\hline $\begin{array}{l}\text { Coastcr } \\
\text { Silagem } \\
\text { Corn sil }\end{array}$ & 31,05 & 93,88 & 7,32 & 1,05 & 85,51 & 62,69 \\
\hline $\begin{array}{l}\text { Conc } \\
\text { Conc }\end{array}$ & 87,91 & 93,91 & 91 & 2,00 & 83,00 & 19,75 \\
\hline $\begin{array}{l}\text { Con } \\
\text { Con }\end{array}$ & 87,37 & 93,21 & 24,32 & 1,58 & 67,31 & 15,8 \\
\hline $\begin{array}{l}\text { Conce } \\
\text { Conce }\end{array}$ & 87,96 & 93,37 & 30,86 & 1,36 & 61,15 & 13,51 \\
\hline $\begin{array}{l}\text { Concentrado } 4 \\
\text { Concentrate } 4\end{array}$ & 86,98 & 93,94 & 19,78 & 2,10 & 76,06 & 14,62 \\
\hline $\begin{array}{l}\text { Concentrado } 5 \\
\text { Concentrate } 5\end{array}$ & 88,02 & 93,16 & 28,03 & 1,48 & 63,65 & 13,72 \\
\hline
\end{tabular}

em quatro camadas de gaze, sendo retirada uma alíquota de $40 \mathrm{~mL}$, para cada animal e tempo de coleta e adicionado $1 \mathrm{~mL}$ de ácido sulfúrico a 50\%, sendo, então, acondicionado em vidros identificados, que foram armazenados em congelador a $-5^{\circ} \mathrm{C}$, para determinação da concentração de amônia $\left(\mathrm{N}-\mathrm{NH}_{3}\right)$ ruminal.

As amostragens dos alimentos fornecidos e das sobras foram feitas diariamente, durante o período de coletas, e acondicionadas em sacos plásticos, devidamente identificados e armazenados em congelador, a $-5^{\circ} \mathrm{C}$, para posteriores análises.

Para cálculo da matéria seca fecal excretada e estimativa da digestibilidade dos nutrientes, utilizouse como indicador externo o óxido crômico $\left(\mathrm{Cr}_{2} \mathrm{O}_{3}\right)$, embrulhado em papel, administrado em duas doses diárias de $10 \mathrm{~g}$ cada, por animal, pela manhã (7h) e à tarde (16h30), entre o 6o e $20^{\circ}$ dia de cada período experimental, segundo SILVA e LEÃO (1979):

Matéria seca fecal

100 x quantidade de indicador fornecido excretada $(\mathrm{kg})=$

$$
\% \text { indicador na MS fecal }
$$

$\mathrm{kg}$ nutriente ingerido - $\mathrm{kg}$ nutriente excretado

Digestibilidade x 100 nutriente $=$

$\mathrm{kg}$ nutriente ingerido

Tabela 3 - Composição bromatológica das dietas experimentais contendo silagem de milho (SM) e fenos de alfafa (FA) e de capim-coastcross (FCC) como fontes de forragens, fornecidas às vacas numa relação forragem:concentrado de $60: 40 \%$

Table 3 - Chemical composition of diets containing corn silage (SC), alfalfa ( $\mathrm{AH})$ and coastcross bermudagrass $(\mathrm{CCH})$ hays as forage sources fed at 60:40 forage to concentrate ratio fed dairy cows

\begin{tabular}{lccccccc}
\hline Dietas & MS \% & MO & PB & EE & CT & FDN & NDT \\
Diets & $D M \%$ & $O M$ & $C P$ & $E E$ & $T C$ & $N D F$ & $T D N$ \\
\hline \multicolumn{7}{c}{ \% na MS } \\
\% in DM \\
\hline FA & 75,02 & 91,82 & 15,00 & 1,34 & 75,48 & 33,08 & 60,40 \\
$A H$ & & & & & & & \\
FCC & 76,86 & 94,07 & 16,37 & 1,06 & 76,64 & 45,89 & 67,00 \\
$C C H$ & & & & & & \\
SM & 35,94 & 93,92 & 17,16 & 1,22 & 75,54 & 39,07 & 67,60 \\
$C S$ & & & & & & & \\
FA+SM & 47,47 & 93,08 & 15,16 & 1,51 & 76,41 & 35,77 & 61,40 \\
$\begin{array}{l}A H+C S \\
\text { FCC+SM }\end{array}$ & 50,37 & 93,84 & 16,92 & 1,15 & 75,77 & 41,98 & 73,31 \\
$C C H+C S$ & & & & & & \\
\hline
\end{tabular}


As coletas de fezes foram realizadas nos três períodos, diretamente do reto, segundo metodologia descrita por ZINN e OWENS (1993), do $17^{\circ}$ ao $20^{\circ}$ dia de cada período experimental onde as amostras foram acondicionadas em sacos plásticos, identificadas por animal e período experimental e guardadas em congelador a $-5^{\circ} \mathrm{C}$. Ao final de cada período experimental, foram descongeladas à temperatura ambiente, homogeneizadas manualmente e colocadas em pratos de papel alumínio, procedendo-se à pré-secagem em estufa de ventilação forçada a $65^{\circ} \mathrm{C}$, por 72 horas. A seguir, foram moídas em moinho tipo Willey, com peneira de $1 \mathrm{~mm}$ e homogeneizadas, para a confecção de amostras compostas por animal, com base no peso seco, para cada período, e armazenadas em vidros com tampa de polietileno, devidamente identificados.

As análises de matéria seca, nitrogênio total, fibra detergente neutro, extrato etéreo e cinzas dos alimentos fornecidos, das sobras e das fezes e de nitrogênio total do leite foram determinadas conforme SILVA (1990). Para a estimativa da proteína bruta total do leite, utilizou-se o fator de conversão de 6,38. O teor de cromo nas fezes foi determinado segundo WILLIAMS et al. (1962), usando-se o espectrofotômetro de absorção atômica.

Os teores de carboidratos totais (CT) dos alimentos fornecidos, das sobras e das fezes e os nutrientes digestíveis totais (NDT) consumidos foram calculados segundo SNIFFEN et al. (1992): $\mathrm{CT}=100-(\% \mathrm{~PB}+$ $\%$ EE $+\%$ CINZAS $) ;$ NDT $=($ PBing - PBfecal $)+$ $($ CTing - CTfecal $)+2,25$ (EEing - EEfecal), em que: PBing $=$ proteína bruta ingerida $; \mathrm{CTing}=$ carboidratos totais ingeridos; e EEing = extrato etéreo ingerido.

Para a corrigir o leite para $4,0 \%$ de gordura (LCG), utilizou-se a equação do NRC (1989): $\mathrm{LCG}=$ $0,4(\mathrm{~kg}$ de leite $)+15(\mathrm{~kg}$ de gordura $)$.

Para a determinação do nitrogênio amoniacal $\left(\mathrm{N}-\mathrm{NH}_{3}\right)$, foi realizada centrifugação das amostras a $10.000 \mathrm{rpm}$, por $15 \mathrm{~min}$., utilizando metodologia segundo FENNER (1965).

A análise das variáveis de produção de leite, produção de leite corrigida a $4,0 \%$ de gordura e porcentagem de gordura e proteína do leite, bem como do consumo dos nutrientes, foi realizada por intermédio da análise de variância, segundo LUCAS (1956), de acordo com o modelo:

$$
\mathrm{Y}_{\mathrm{ij}}=\mu+\mathrm{T}_{\mathrm{i}}+\mathrm{B}_{\mathrm{j}}+\mathrm{e}_{\mathrm{ij}}
$$

em que: $Y_{i j}=$ observação relativa à vaca que recebeu o tratamento $\mathrm{i} ; \mu=$ média geral; $\mathrm{T}_{\mathrm{i}}=$ efeito do tratamento $\mathrm{i}(\mathrm{i}=1$ a 5$) ; \mathrm{B}^{\mathrm{j}}=$ efeito do bloco $\mathrm{j}(\mathrm{j}=1 \mathrm{e}$ 2), $\mathrm{e} ; \mathrm{e}_{\mathrm{ij}}=$ erro experimental.
Para a análise das variáveis da digestibilidade de matéria seca (MS), matéria orgânica (MO), proteína bruta $(\mathrm{PB})$, extrato etéreo (EE), fibra em detergente neutro (FDN) e carboidratos totais (CT), utilizando-se os dados dos três períodos experimentais, adotou-se o modelo relativo ao delineamento inteiramente casualizado:

$$
\mathrm{Y}_{\mathrm{ij}}=\mu+\mathrm{T}_{\mathrm{i}}+\mathrm{e}_{\mathrm{ij}}
$$

em que: $Y i j=$ observação relativa à vaca que recebeu o tratamento $i ; \mu=$ média geral; $T_{i}=$ efeito do tratamento i ( $\mathrm{i}=1$ a 5 ), e; $\mathrm{e}_{\mathrm{ij}}=$ erro experimental.

Os dados de concentração de amônia e pH do líquido ruminal foram analisados por meio de delineamento inteiramente casualizado, em esquema de parcelas subdivididas, em que as rações constituíram as parcelas e os tempos de amostragem, as subparcelas. Os resultados foram interpretados, estatisticamente, por meio de análises de variância e regressão, usando o Sistema de Análise Estatística e Genética - SAEG 8.0 (UNIVERSIDADE FEDERAL DE VIÇOSA, 1998). A comparação de médias para as variáveis qualitativas foram feitas pelo teste de Tukey, a 5\% de probabilidade.

\section{Resultados e Discussão}

O consumo de matéria seca, expresso nas diferentes formas, não diferiu $(\mathrm{P}>0,05)$ entre as dietas (Tabela 4).

As vacas que receberam dietas contendo $\mathrm{FA}+\mathrm{SM}$ e $\mathrm{FCC}+\mathrm{SM}$ ingeriram 1,81 e 2,11 kg de matéria seca a mais em relação às que receberam os respectivos fenos, como fonte única de volumoso, nas dietas. Segundo NELSON e SATTER (1992), rações à base de feno aparentemente estão sujeitas a limitações do consumo pelo enchimento ruminal, sob demandas semelhantes de energia, que dietas à base de silagem, em decorrência da maior solubilidade dos nutrientes verificados na silagem.

DHIMAN e SATTER (1997) relataram que a associação de feno e silagem proporcionou maior uniformização no consumo de nutrientes, diminuindo, assim, a possibilidade de algum nutriente ser limitante para os animais, além de influir no consumo de feno.

As diferentes dietas apresentaram semelhantes, o que pode estar em função da presença do concentrado utilizado para atender os requerimentos de energia, proteína e minerais.

O consumo de matéria orgânica, expresso em $\mathrm{kg} / \mathrm{dia}$, não foi influenciado $(\mathrm{P}>0,05)$ pelas rações experimentais. 
O consumo de proteína bruta não diferiu $(\mathrm{P}>0,05)$ entre as dietas (Tabela 4). Observou-se que todas as rações supriram os requerimentos diários de proteína bruta para a produção média de leite dos animais, que, segundo o NRC (1989), seria de 2,234 kg de PB/ vaca. A tendência de maior ingestão de proteína bruta pelos animais que receberam a dieta contendo silagem de milho pode estar associada à maior participação do farelo de soja no concentrado.

Para o consumo de extrato etéreo e carboidratos totais, expressos em kg/dia, os mesmos não foram influenciados $(\mathrm{P}>0,05)$ entre as dietas experimentais.
$\mathrm{O}$ consumo de fibra em detergente neutro, que variou de 1,25 (feno de alfafa) a 1,59\% do peso vivo (feno decapim-coastcross), não foi influenciado $(\mathrm{P}>0,05)$ pelas dietas (Tabela 4). Segundo MERTENS (1996), ótima produção de leite corrigida a $4 \%$ de gordura é obtida quando o consumo situa-se na faixa de 1,1 a 1,2\% do peso vivo. Observando a Tabela 4, constata-se que somente aqueles animais que receberam ração contendo feno de alfafa, como fonte única de volumoso, apresentaram consumo próximo a esta faixa.

O consumo de nutrientes digestíveis totais, que variou de 11,30 a 14,04 kg/dia, para o feno de alfafa

Tabela 4 - Consumos médios diários estimados dos nutrientes das dietas experimentais Table 4 - Estimated average nutrients intake of the experimental diets

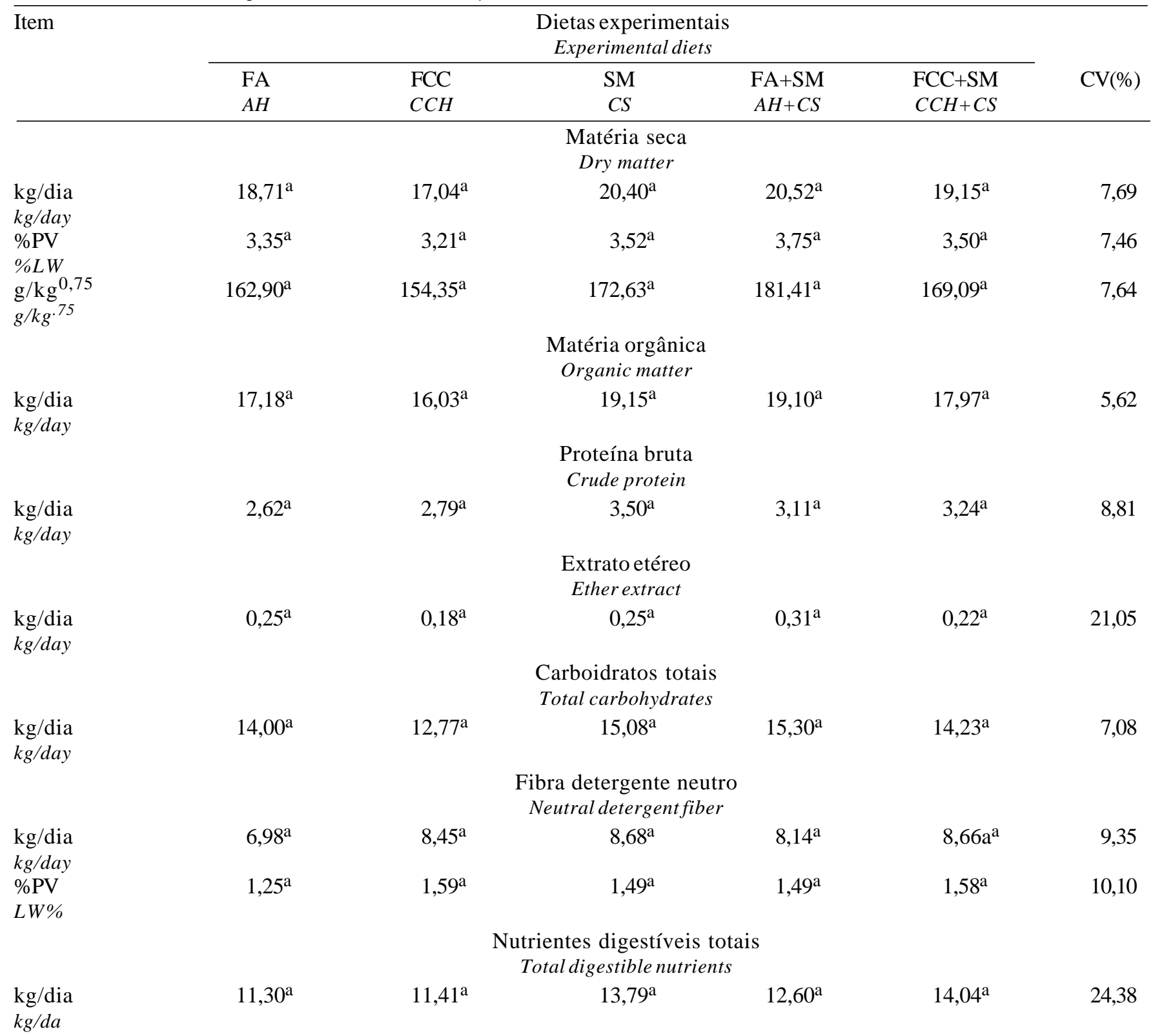

Médias na mesma linha, seguidas pela mesma, letra não diferem pelo teste Tukey (5\%). 
Rev. bras. zootec.

e a silagem de milho + feno de capim-coastcross, respectivamente, também não foi afetado $(\mathrm{P}>0,05)$ pelas dietas experimentais (Tabela 4). Como observado para a proteína bruta, todas as dietas atenderam às exigências médias diárias dos nutrientes digestíveis totais para mantença e produção de leite, que, segundo o NRC (1989), seria de 10,6 kg NDT/vaca.

O excesso no consumo de PB $(0,386$ a $1,266 \mathrm{~kg} / \mathrm{dia})$ e $\operatorname{NDT}(0,70$ a $3,44 \mathrm{~kg} / \mathrm{dia})$ pode ter ocorrido em virtude dos animais estarem utilizando esses nutrientes para o ganho de peso, no decorrer do período experimental, onde foram registrados ganhos de 0,$285 ; 0,325 ; 0,698$; 0,269; e $0,579 \mathrm{~kg} / \mathrm{dia}$ para os animais consumindo feno de alfafa (FA), feno de capim-coastcross (FCC), silagem de milho (SM), FA+SM e FCC+SM, respectivamente, considerando-se as pesagens dos animais no início e no final de cada período experimental.

A digestibilidade aparente da matéria seca, que variou de 64,10 (feno de alfafa) a 73,73\% (silagem de milho), foi maior $(\mathrm{P}<0,05)$ para a dieta contendo silagem de milho em relação às contendo os fenos de alfafa e capim-coastcross (Tabela 5). Estes valores se encontram dentro da faixa registrada por outros autores, em estudos conduzidos com os volumosos citados, em associação, ou como fonte única de forragem nas rações (NELSON e SATTER, 1990; WEST et al., 1995).

A digestibilidade da matéria orgânica não foi influenciada $(\mathrm{P}>0,05)$ pelas dietas.

Quanto à proteína bruta, observou-se maior $(\mathrm{P}<0,05)$ digestibilidade aparente para a dieta contendo silagem de milho (71,69\%), que, por sua vez, não diferiu daquela contendo silagem associada com feno de capim-coastcross $(61,76 \%)$.

Os resultados do presente estudo para a digestibilidade aparente da matéria seca, e proteína bruta, para a dieta contendo silagem de milho, foram, respectivamente, 73,73 e 71,69\%, mostrando-se superiores aos encontrados por MORA et al. (1996), em ensaio de digestibilidade aparente, 69,5 e 69,0\%, respectivamente. A digestibilidade aparente do extrato etéreo apresentou variação de 32,38 a 58,61\%, para o feno de capim-coastcross e este associado à silagem de milho, respectivamente.

A digestibilidade aparente para os carboidratos totais não foi influenciada $(\mathrm{P}>0,05)$ pelas dietas, que variou de 50,09 (feno de alfafa) a 65,54\% (silagem de milho).

Para a fibra em detergente neutro, a digestibilidade aparente apresentou maior $(\mathrm{P}<0,05)$ valor para a ração contendo silagem de milho como única fonte de volumoso. Conforme BEAUCHEMIN e BUCHANANSMITH (1990), maior digestibilidade para rações contendo silagem seria esperada, pois, no decorrer da digestão, a silagem promove maior desintegração das partículas em menor tempo e, ao ser comparada com rações contendo feno, durante a mastigação e ruminação, resultando em maior passagem de partículas pelo rúmen.

A concentração de amônia ruminal não foi influenciada $(\mathrm{P}>0,05)$ pelas dietas, mas foi afetada pelo tempo de amostragem, registrando-se efeito $(\mathrm{P}<0,05)$ quadrático, com a equação: $\mathrm{Y}=11,9525+3,27024 \mathrm{~T}$ -

Tabela 5 - Digestibilidades aparentes médias (\%) dos nutrientes das dietas experimentais

Table 5 - Nutrient apparent digestibilities of the experimental diets

\begin{tabular}{|c|c|c|c|c|c|c|}
\hline \multirow[t]{2}{*}{ Item } & \multicolumn{5}{|c|}{$\begin{array}{c}\text { Dietas experimentais } \\
\text { Experimental diets }\end{array}$} & \multirow[b]{2}{*}{$\mathrm{CV}(\%)$} \\
\hline & $\begin{array}{l}\mathrm{FA} \\
\mathrm{AH}\end{array}$ & $\begin{array}{l}\mathrm{FCC} \\
\mathrm{CCH}\end{array}$ & $\begin{array}{c}\mathrm{SM} \\
C S\end{array}$ & $\begin{array}{c}\mathrm{FA}+\mathrm{SM} \\
A H+C S\end{array}$ & $\begin{array}{l}\mathrm{FCC}+\mathrm{SM} \\
\mathrm{CCH}+\mathrm{CS}\end{array}$ & \\
\hline $\begin{array}{l}\text { Matéria seca } \\
\text { Dry matter }\end{array}$ & $64,10^{\mathrm{b}}$ & $64,64^{\mathrm{b}}$ & $73,73^{\mathrm{a}}$ & $67,48^{\mathrm{ab}}$ & $70,19^{\mathrm{ab}}$ & 7,55 \\
\hline $\begin{array}{l}\text { Matéria orgânica } \\
\text { Organic matter }\end{array}$ & $65,73^{a}$ & $63,83^{\mathrm{a}}$ & $73,06^{\mathrm{a}}$ & $67,07^{\mathrm{a}}$ & $69,64^{\mathrm{a}}$ & 12,23 \\
\hline $\begin{array}{l}\text { Proteína bruta } \\
\text { Crude protein }\end{array}$ & $48,27^{\mathrm{c}}$ & $58,72^{b c}$ & $71,69^{\mathrm{a}}$ & $48,88^{\mathrm{c}}$ & $61,76^{\mathrm{ab}}$ & 11,67 \\
\hline $\begin{array}{l}\text { Extrato etéreo } \\
\text { Ether extract }\end{array}$ & $46,97^{\mathrm{ab}}$ & $32,38^{c}$ & $37,00^{\mathrm{bc}}$ & $44,38^{b c}$ & $58,61^{\mathrm{a}}$ & 19,07 \\
\hline $\begin{array}{l}\text { Carboidratos totais } \\
\text { Total carbohydrates }\end{array}$ & $50,09^{\mathrm{a}}$ & $52,28^{a}$ & $65,54^{\mathrm{a}}$ & $60,29^{a}$ & $55,13^{\mathrm{a}}$ & 21,58 \\
\hline $\begin{array}{l}\text { Fibra detergente neutro } \\
\text { Neutral detergent fiber }\end{array}$ & $53,56^{\mathrm{b}}$ & $50,32^{\mathrm{bc}}$ & $64,07^{\mathrm{a}}$ & $44,17^{\mathrm{c}}$ & $44,20^{\mathrm{bc}}$ & 7,64 \\
\hline
\end{tabular}

Médias na mesma linha, seguidas pela mesma letra, não diferem pelo teste Tukey a $5 \%$ de probabilidade.

Means followed by the same letter, in a row, are not different $(P<.05)$ by Tukey test. 
$0,613844 \mathrm{~T}^{2} \mathrm{R}^{2}=0,865$. Estimou-se a concentração máxima de amônia ruminal de $16,3 \mathrm{mg} / 100 \mathrm{~mL}$, para o tempo de 2,66 horas após a alimentação. Segundo autores (SATTER e SLYTER, 1974, e COLLINS e PRITCHARD, 1992) a concentração mínima de amônia ruminal necessária é de $5 \mathrm{mg} \mathrm{N}-\mathrm{NH}_{3} / 100 \mathrm{~mL}$ de fluido ruminal para crescimento dos microrganismos sendo os valores médios determinados de amônia ruminal para as diferentes dietas, neste estudo, atendem essa exigência.

Para os valores de $\mathrm{pH}$ do líquido ruminal encontrados nos diferentes tempos de amostragem, verificou-se que os valores médios altos, em decorrência de possível contaminação com a saliva, devido ao método de coleta utilizado, via sonda esofagiana. $\mathrm{O}$ valor médio de 7,28 de $\mathrm{pH}$, registrado para o tempo zero, pode estar associado ao fato de que, no jejum, $\mathrm{o} \mathrm{pH}$ ruminal se encontra próximo à neutralidade, segundo KOLB (1984). Observou-se que, duas horas após o fornecimento de alimento, houve decréscimo do pH (média de 6,91) e, em seguida, elevou-se, registrando o valor médio de 7,19 , às seis horas após alimentação. $\mathrm{O}$ pH ruminal não foi afetado $(\mathrm{P}>0,05)$ pelas dietas, mas foi influenciado pelo tempo de amostragem, detectando-se efeito quadrático $(\mathrm{P}<0,05)$ com equação: $\mathrm{Y}=7,2384-0,150925 \mathrm{~T}+0,0249375 \mathrm{~T}^{2} \mathrm{R}^{2}=0,54$. Estimouse o valor mínimo de 7,01 para o tempo de 3,02 horas. WEST et al. (1998), em estudos sobre parâmetros ruminais, em vacas leiteiras, obtiveram valores médios de pH de 7,16 e 7,19 para dietas contendo feno de capim- coastcross associado à silagem de milho e silagem de capim-coastcross associada à silagem de milho, respectivamente, os quais foram próximos aos deste estudo.

Os animais que receberam dietas contendo silagem de milho e está associada ao feno de alfafa revelaram maiores produções de leite $(\mathrm{kg} / \mathrm{dia})$, registrando-se, respectivamente, 24,17 e $21,16 \mathrm{~kg}$ de leite por dia (Tabela 6). Contudo a dieta contendo silagem de milho associada ao feno de alfafa, por sua vez, foi semelhante $(\mathrm{P}>0,05)$ às demais dietas testadas. Este comportamento parece não ter explicação lógica, uma vez que não ocorreram diferenças entre os consumos de matéria seca das dietas.

Para a produção de leite corrigida para $4 \%$ de gordura, registrou-se comportamento semelhante ao de produção de leite em kg/dia (Tabela 6) em que maior $(\mathrm{P}>0,05)$ produção leiteira foi verificada para os animais que receberam a dieta contendo silagem de milho e esta associada ao feno de alfafa, sendo que a última (SM+FA) não diferiu das demais dietas.

Segundo MERTENS (1996), produções máximas de leite (corrigida para 4\% de gordura) podem ser obtidas quando o consumo diário de FDN encontra-se em torno de 1,1 a $1,2 \%$ do peso vivo animal. Os consumos de FDN observados no presente estudo variaram de 1,25 a $1,59 \%$ do peso vivo, sendo superiores aos preconizados por esse autor.

Os teores médios estimados para gordura e proteína do leite do presente estudo não diferiram $(\mathrm{P}>0,05)$

Tabela 6 - Estimativas das produções médias diárias de leite $(P L)$ e de leite corrigido para $4 \%$ de gordura (PLC) e dos teores de gordura e proteína do leite

Table 6 - Estimates of average daily milk (DMY) and 4.0 fat corrected milk yields (FCMY) and fat and crude protein contents of milk

\begin{tabular}{|c|c|c|c|c|}
\hline \multirow[b]{2}{*}{$\begin{array}{l}\text { Rações } \\
\text { Diets }\end{array}$} & \multirow[b]{2}{*}{$\begin{array}{c}\text { PL (kg/dia }) \\
D M Y(k g / \text { day })\end{array}$} & \multirow[b]{2}{*}{$\begin{array}{c}\text { PLC }(\mathrm{kg} / \text { dia }) \\
F C M Y(k g / \text { day })\end{array}$} & \multicolumn{2}{|c|}{$\begin{array}{l}\text { Composição do leite } \\
\text { Milk composition }\end{array}$} \\
\hline & & & $\begin{array}{c}\text { Gordura }(\%) \\
\text { Fat }\end{array}$ & $\begin{array}{c}\text { Proteína (\%) } \\
\text { Protein }\end{array}$ \\
\hline FA & $20,86^{b}$ & $19,80^{b}$ & $3,66^{\mathrm{a}}$ & $3,64^{\mathrm{a}}$ \\
\hline $\begin{array}{l}A H \\
\text { FCC } \\
C C H\end{array}$ & $20,30^{\mathrm{b}}$ & $19,11^{b}$ & $3,61^{\mathrm{a}}$ & $3,20^{\mathrm{a}}$ \\
\hline $\begin{array}{l}\mathrm{SM} \\
C S\end{array}$ & $24,36^{\mathrm{a}}$ & $25,56^{\mathrm{a}}$ & $4,33^{\mathrm{a}}$ & $3,43^{\mathrm{a}}$ \\
\hline $\begin{array}{l}\mathrm{FA}+\mathrm{SM} \\
A H+C S\end{array}$ & $21,30^{\mathrm{ab}}$ & $22,19^{\mathrm{ab}}$ & $4,28^{\mathrm{a}}$ & $3,50^{\mathrm{a}}$ \\
\hline $\begin{array}{l}\mathrm{FCC}+\mathrm{SM} \\
\mathrm{CCH}+\mathrm{CS}\end{array}$ & $19,83^{b}$ & $19,47^{b}$ & $3,88^{\mathrm{a}}$ & $3,49^{\mathrm{a}}$ \\
\hline $\begin{array}{l}\text { Média } \\
\text { Mean }\end{array}$ & 21,33 & 21,23 & 3,95 & 3,45 \\
\hline $\mathrm{CV}(\%)$ & 4,69 & 5,14 & 5,93 & 7,36 \\
\hline
\end{tabular}

Médias na mesma coluna, seguidas pela mesma letra, não diferem pelo teste Tukey a $5 \%$ de probabilidade.

Means followed by the same letter, in a column, are not different $(P<.05)$ by Tukey test. 
entre as dietas (Tabela 6). Os teores médios de 3,95 e $3,45 \%$, registrados, respectivamente, para gordura e proteína, situam-se dentro da faixa encontrada por NELSON e SATTER (1992), que variou de 3,96 a $3,45 \%$, para as respectivas variáveis.

O custo diário com alimentação e margem bruta em função da produção por animal, relativos às cinco dietas, foram calculados considerando somente os custos com alimentação. $\mathrm{O}$ custo diário ( $\mathrm{R} \$$ dia) foi de 3,$99 ; 3,12 ; 3,67 ; 4,15$; e 3,48 para as rações contendo feno de alfafa (FA), feno de capimcoastcross (FCC), silagem de milho (SM), FA+SM, e $\mathrm{FCC}+\mathrm{SM}$, respectivamente. A margem bruta $(\mathrm{R} \$ /$ $\mathrm{vaca} /$ dia) calculadas para as mesmas rações foram de 1,$45 ; 2,20 ; 2,61 ; 1,35 ;$ e 1,73 , respectivamente.

\section{Conclusões}

Os consumos dos nutrientes não foram influenciados pelas dietas experimentais, contudo registrou-se maiores produções de leite naquelas rações contendo silagem de milho.

Os teores de gordura e proteína bruta do leite não foram afetados pelas rações experimentais.

O uso de determinados volumosos, para vacas lactantes, estaria na dependência do custo dos alimentos concentrados disponíveis na região e do preço do leite pago ao produtor, bem como do potencial genético dos animais.

\section{Referências Bibliográficas}

AMARAL, J.L. Palha de arroz suplementada com fenos de rama de mandioca e amora, farinha de pena e sangue na alimentação de ruminantes. Viçosa, MG: UFV, 1994. 91p. Tese (Doutorado em Zootecnia) - Universidade Federal de Viçosa, 1994.

BEAUCHEMIN, K.A., BUCHANAN-SMITH, J.G. 1990. Effects of fiber source and method of feeding on chewing activities, digestive function, and productivity of dairy cows. J. Dairy Sci., 73(3):749-762.

BEHMER, M.L.A. 1984. Tecnologia do leite: produção, industrialização e análise. 13.ed. São Paulo: Nobel. p.100-108.

BELYEA, R.A., COPPOCK, C.E., MERRILL, W.G. et al. 1974. Effects of silage based diets on feed intake, milk production, and body weight of dairy cows. J. Dairy Sci., 58(8):1328.

BRODERICK, G.A. 1985. Alfalfa silage or hay versus corn silage as sole forage for lactating dairy cows. J. Dairy Sci., 68(12):3262-3271.

CODAGNONE, H.C.V., CARDOSO, R.M., CASTRO, A.C.G. et al. 1988. Silagem de milho e feno de aveia (Avena bizantina, L.) na alimentação de vacas em lactação. R. Soc. Bras. Zootec., 17(6):487-497.

COLLINS, R.M., PRITCHARD, R.H. 1992. Alternate day supplementation of corn gluten meal fed to ruminants. J. Anim. Sci., 70(12):3899-3908.
DHIMAN, T.R., SATTER, L.D. 1997. Yield response of dairy cows fed different proportions of alfalfa silage and corn silage. J. Dairy Sci., 80(9):2069-2087.

FENNER, H. 1965. Method for determining total volatile bases in rumen fluid by steam destilation. J. Dairy Sci., 48(4):249-251.

GOMES, B.V. Influência das características químicas e físicas das forragens sobre o consumo, degradação e cinética da digestão animal. Viçosa, MG: UFV, 1991. 116p. Tese (Doutorado em Zootecnia) - Universidade Federal de Viçosa. 1991.

GRIEVE, D.G., STONE, J.B., MAcLELOD, G.K. et al. 1980. All silage forage programs for dairy cattle. II. Performance through three lactations. J. Dairy Sci., 63(4):594-600.

HOLTER, J.B., JOHNS, W., URBAN JR., W.E. 1974. No associative effects between corn and haycrop silages fed to lactating dairy cows. J. Dairy Sci., 58(11): 1865.

HOOVER, W.H. 1986. Chemical factors involved in ruminal fiber digestion. J. Dairy Sci., 69(10):2755-2766.

HOOVER, W.H., STOKES, S.R. 1991. Balancing carbohydrates and proteins for optimum rumen microbial yield. J. Dairy Sci., 74(10):3630-3644.

KOLB, E. 1984. Fisiologia veterinária. 4.ed. Rio de Janeiro: Guanabara Koogan. 612p.

LAVEZZO, O.E.N.M., LAVEZZO, W, WECHSLER, F.S. 1998. Estádio de desenvolvimento do milho. 3. Avaliação de silagens por intermédio de parâmetros de fermentação ruminal. R. Soc. Bras. Zootec., 27(1):171-178.

LENG, R.A., NOLAN, I.V. 1984. Nitrogen metabolism in the rumen. J. Dairy Sci., 67(5): 1072-1089.

LUCAS, H.L. 1956. Switchback trials for more than two treatments. J. Dairy Sci., 39(2):146-154.

MERTENS, D.R. 1996. Comparing forage sources in dairy rations containing similar neutral detergent fiber concentrations. In: U.S. DAIRY FORAGE RESEARCH CENTER, 1995. Research Summaries. USDA, ARS. p.87-90.

MORA, P.J.G., VALADARES FILHO, S.C., LEÃO, M.I. et al. 1996. Digestibilidade aparente dos nutrientes e energia líquida da silagem de milho (Zea mays L.) para vacas lactantes. R. Soc. Bras. Zootec., 25(2): 357-368.

NATIONAL RESEARCH COUNCIL - NRC. 1989. Nutrients requirements of dairy cattle. 6.ed. Washington, D.C.: National Academy Press. 157p.

NELSON, W.F., SATTER, L.D. 1990. Effect of stage of maturity and method of preservation of alfalfa on production by lactating dairy cows. J. Dairy Sci., 73(7):1800.

NELSON, W.F., SATTER, L.D. 1992. Impact of stage of maturity and method of preservation of alfalfa on digestion in lactating dairy cows. J. Dairy Sci., 75(6):1571.

NOLLER, C.H., NASCIMENTO JR., D., QUEIROZ, D.S. Determinando as exigências nutricionais de animais em pastejo. In: SIMPÓSIO SOBRE MANEJO DE PASTAGENS, 13., 1996, Piracicaba. Anais... Piracicaba, SP: FEALQ, 1997. p.319-351.

OBARA, Y., DELLOW, D.W., NOLAN, J.V. 1991. The influence of energy-rich supplements on nitrogen kinetics in ruminants. In: TSUDA, T., SASAKI, Y., KAWASHIMA, R. (Eds.) Physiological aspects of digestion and metabolism in ruminants. Tokyo: Academic Press. p.515-539.

ORTOLANI, E.L. 1981. Considerações técnicas sobre o uso da sonda esofágica na colheita do suco do rúmen de bovinos para mensuração do pH. Arq. Esc. Vet. UFMG, 33(2):269-275.

RUSSELL, J.B. 1992. Minimizing ruminant nitrogen losses. In: SIMPÓSIO INTERNACIONAL EM RUMINANTES, 1992, Lavras. Anais... Lavras: ESAL, p.47-64.

RUSSELL, J.B., O'CONNOR, J.D., FOX, D.G. et al. 1992. A net carbohydrate and protein system for evaluating cattle 
diets. I - Ruminal fermentation. J. Anim. Sci., 70(11):35513561.

SATTER, L.D., SLYTER, L.L. 1974. Effect of ammonia concentration on rumen microbial protein production in vitro. Brit. J. Nutr., 32(2):199-205.

SCHINGOETHE, D.J. 1984. Interrelationships between protein solubility and energy sources for cattle. Can. J. Anim. Sci., 64(1):199-200 (Suppl. 1).

SILVA, D.J. 1990. Análise de alimentos: métodos químicos e biológicos. Viçosa, MG: UFV. 165p.

SILVA, J.F.C., LEÃO, M.I. 1979. Fundamentos de nutrição dos ruminantes. Piracicaba: Livroceres. 380p.

SNIFFEN, C.J., O'CONNOR, J.D., VAN SOEST, P.J. et al. 1992. A net carbohydrate and protein system for evaluating cattle diets; II. Carbohydrate and protein availability. J. Anim. Sci., 70(11):3562-3577.

UNIVERSIDADE FEDERAL DE VIÇOSA - UFV. SAEG. (Programa de Análises Estatísticas e Genéticas). Viçosa, MG, 1998. (Versão 8.0).

VAN SOEST, P.J. 1965. Symposium on factors influencing the voluntary intake of herbage by ruminants: voluntary intake in relation to chemical composition and digestibility. J. Anim. Sci., 24(3):834-843.

VAN SOEST, P.J. 1994. Nutritional ecology of the ruminant. Ithaca: Cornell Univ. Press. 476p.
WEST, J.W., MANDEBVU, P., HILL, G.M. et al. 1998. Intake, milk yield, and digestion by dairy cows fed diets with increasing fiber content from bermudagrass hay on silage. J. Dairy Sci., 81:1599-1607.

WEST, J.W., MATHIS, M.J., HILL, G.M. et al. 1995. Effects of dietary forage source and fiber content on intake and lactational performance of dairy cows. Annual Report. Georgia: Depart. of Animal and Dairy Science. The University of Georgia. 5p.

WILliaMS, C.H., DAVID, D.J., IISMA, O. 1962. The determination of chromic oxide in feces samples by atomic absorption spectrophotometry. J. Agri. Sci., 59(2):381-385.

ZINN, R.A., OWENS, F.N. 1993. Ruminal escape protein for lightweight feedlot calves. Can. J. Anim. Sci., 71(6):1677-1687.

Recebido em: 18/05/00

Aceito em: 20/02/01 